\title{
PROCESSES OF ENRICHMENT OF SURFACE WATER WITH NUTRIENTS DUE TO STRONG WINDS BLOWING ON TO A CONTINENTAL SLOPE
}

\author{
By L. H. N. Cooper, D.Sc., F.R.I.C. \\ Chemist at the Plymouth Laboratory
}

(Text-figs. I-4)

Biological and physical evidence suggests that the area south-west of Ireland is one of loss from the Celtic Sea. In winter the shelf water there may cascade to $400 \mathrm{~m}$. or even deeper (Cooper \& Vaux, I949). All the evidence suggests that new water enters the Celtic Sea and English Channel over the continental slope between Ushant and the Sole submarine promontory 250 miles to the west. No evidence exists that the Atlantic surface waters are ever rich enough to account for the enrichment of the English Channel observed in the nineteentwenties. Although the existence then of sufficiently rich oceanic surface water cannot be excluded, it is much more probable that the enrichment was brought about by some form of upwelling. The cause of this is thought to be composite. Only a few times in a century may the component phenomena work together to produce the maximum effect. Each component needs separate study.

There may be two distinct effects of a strong wind blowing on to the continental slope from the south. Such a wind will force light nutrient-poor water against the slope (assumed to extend to the surface of the sea) to form a cushion of considerable depth above sloping isosteres-surfaces of equal density - stable only while the wind lasts (Sandström, I9I8; reproduced by Harvey, 1928, fig. 25 A). Potential energy has become stored in the water. As soon as the wind dies down and the stress is removed from the sea surface, the potential energy is converted to kinetic energy. Each isosteric surface would then oscillate about its mean level. If there were no frictional losses, this oscillation would go on for ever.

The conditions. against an actual continental slope are rather different, since it is usually bordered by a continental shelf. There, when the heavy deeper water rises against the slope, it would spill over the edge on to the continental shelf. Some mixing and enrichment with nutrients of continental shelf water would occur, but the effect is unlikely to be great and it would be important only locally.

But in a submarine valley, such as that at $48^{\circ} \mathrm{I} 3^{\prime}$ N., $9^{\circ} 2 \mathrm{I}^{\prime}$ W., which becomes narrower and shallower as it cuts back into the shelf, such spillage 
water would become canalized. Conditions would come to resemble those which create a tidal bore or eagre in the Rivers Severn and Trent. It would seem probable that such a constricted core or eagre of deep water could be projected for many miles on to the continental shelf whence it would return only slowly on the next downward swing of the boundary layer over deep water. This mechanism would be especially favoured if a submarine valley in the slope heads into one of the shallow troughs which dissect the southwestern Celtic Sea. Indeed it would provide a means for preventing such troughs from silting up.

The inference is that areas of the sea lying immediately shorewards of a submarine valley should be especially favourable for outbursts of phytoplankton not only in spring but in summer as well. Submarine eagres of this kind may well often occur but seem insufficient to account for much enrichment of large areas such as the Celtic Sea.

Except when cascading is occurring (Cooper \& Vaux, I949), waters near the headings of submarine valleys should become richer in total phosphorus and other 'total' nutrients than those lying near to an undissected continental slope.

Sandström (I9I8, p. 234) further developed this idea into his concept of 'jibing' of water masses in a high wind. When the external forces, such as wind stress, acting on the sea water reach a magnitude exceeding the highest possible value which can be sustained by the Archimedean forces, a catastrophe takes place and an entirely new state of affairs is brought about, exactly as when the limit of elasticity of a solid is exceeded.

The maximal value of the Archimedean forces is reached when the isosteres become vertical. Should the external forces exceed that required to produce vertical isosteres, then the surface waters will capsize, as exemplified in detail in Fig. I. Then, light water is brought down beneath heavier, the stability is upset and a strong vertical convection ensues whereby the whole of the water affected is mixed up into one single homogeneous layer. The specific volume of this layer will be equal to the mean specific volume of the strata of which it is composed, and between this and the water beneath there will be a sharply defined difference of density. In the homogeneous layer there will be no isosteres and, consequently, no Archimedean forces will arise, so that the water therein contained will follow without resistance the direction of any external force acting upon it. The circulation will be highly intensive so that the water will continue homogeneous, and exert a continual friction upon the layer beneath, thus maintaining the sharply defined limit of density between the two. This friction occasions a gradual absorption of the water from the lower layer, so that the upper one will tend to increase in volume, density and nutrient content.

Sandström gave to this process the name 'to jibe'. 'Jibe' is a variant of 'gibe' and means 'to taunt'; either 'gybe' or 'jib' may have been intended. 
Their meaning is to swing from one side of a mast to the other. ' $\mathrm{Jib}$ ' has other meanings; applied to a horse it signifies to stop suddenly, to move restively sideways and backwards. The term 'to jib' could be used but is not particularly appropriate for the present purpose. 'Capsize' is more fitting. ${ }^{1}$

In Fig. I, panels C and D, as applied to the Celtic Sea, part of the energy of the wind will be expended on raising the level of the water over the continental shelf (i.e. in the Celtic Sea), part in forcing water through escape channels, such as the Straits of Dover and the North Channel, and part in initiating a cyclonic circulation of water to escape south-west of Ireland.

South-west of Ireland the gales most likely to provoke capsizing of water masses will be from the south-west and west, and these are the prevailing winds and those which most often reach gale force. They are commonest in winter and will then combine with cascading and resonance phenomena in the 'South Porcupine submarine indentation' to produce vertical mixing to a very considerable depth (cf. Fig. 2). The waters most concerned will be either oceanic surface waters or water recently cascaded from the continental shelf. There is in this area only rarely a mechanism for enriching the continental shelf with deep nutrients on any considerable scale. Even when enrichment occurs here, the dominant cyclonic circulation will tend to carry the surface water away from the Celtic Sea. The waters over the Porcupine Bank might, however, benefit. Whenever cascading plays a part it will tend to reduce enrichment from deep water by any other mechanism.

Along the southern edge of the Celtic Sea, the strong winds most favourable for capsizing would blow from the south-east or south. These winds are less common than the south-westerlies and westerlies. Moreover, in this area, there is much less cascade water so that, if capsizing occurs, it may bring about mixing with the deeper North Atlantic Central water and even with the Mediterranean or Gulf of Gibraltar water at 800-I200 m. depth, both relatively rich in nutrients (Cooper, $1952^{\circ}$ ). All in all, the most favourable conditions for enrichment of the southernmost Celtic Sea by capsizing are likely to occur after the breakdown of the summer thermocline in autumn. Southerly gales in November and December are likely to be more effective in bringing up nutrients than those in February or March. The usual cyclonic circulation of the Celtic Sea will tend to transport such enriched water on to the continental shelf and into the English Channel.

Conditions to initiate capsizing of water masses are likely to occur over continental slopes backed by extensive shallow seas, for there the surface ocean waters are relatively free to press inwards, whereas the root of the water mass will be stopped completely by the continental slope.

1 The writer would prefer to introduce the term 'culbute' derived from the French culbuter which suggests all that 'capsize' and 'somersault' do, but much destructive power as well. Majority opinion in this laboratory is that addition of yet another word to the technical jargon of science cannot be justified and that 'capsize' will serve (see Addendum, p. 463). 


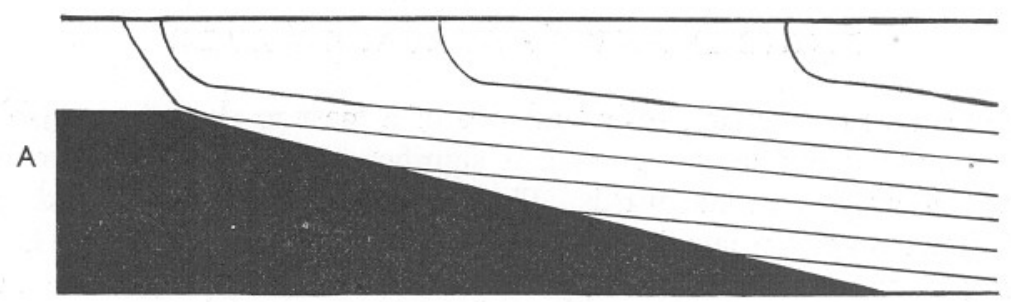

Homogeneous surface layer

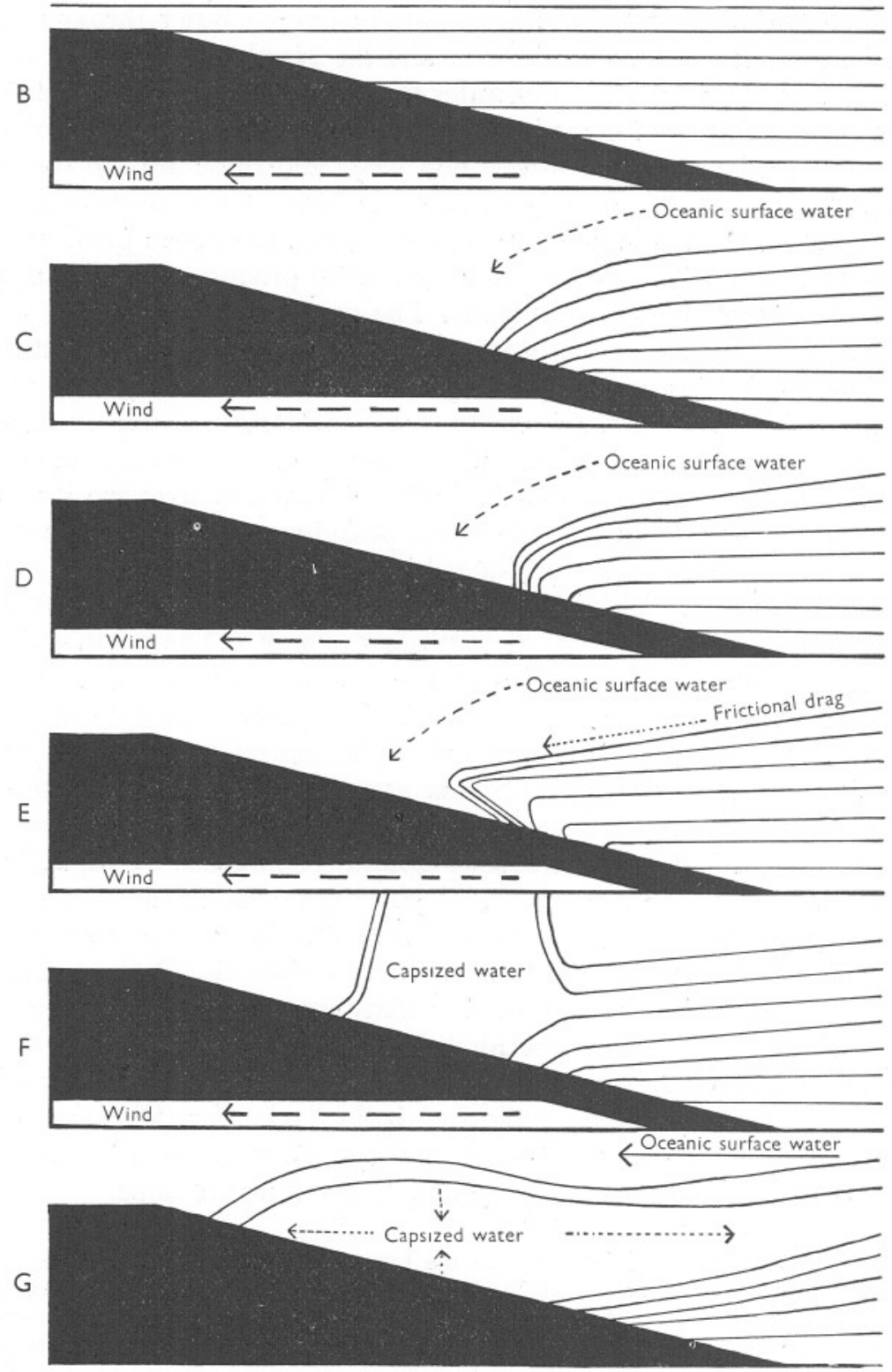

Fig. I. 
Capsizing is essentially a wave phenomenon and may be compared with the breaking of a roller approaching a beach. By analogy with what happens to a swell approaching an ordinary coastal bay, over a submarine terrain such as that illustrated by Cooper (1952, fig. IO), there should be a tendency for the destructive energy created by capsizing to be concentrated over the submarine spurs and for the headings of the valleys to be relatively quiet. Capsizing as a mechanism for surface enrichment with nutrients is likely to be more effective over strongly dissected sections of the continental slope than over smooth areas.

In September I950, Dr C. F. Mortimer kindly allowed me to experiment with his model built to illustrate the observed effect on water movements of a strong wind blowing along a stratified lake, Windermere. Mortimer's model, developed quite independently, resembles that illustrated by Sandström (I9I8, fig. 45), except that it has sloping ends. At the time interest was concentrated on establishing that internal waves from a distant source could produce upwelling phenomena. Although something of the sort could be made to happen, the scale did not seem adequate to account for observations in the ocean.

In these experiments the process of capsizing and the destructive turbulence resulting was demonstrated, yet, I regret to say, it was not until 6 months later, when the theory of capsizing over a continental slope had been further developed from Sandström's work, that the behaviour of the model was understood (see Addendum, p. 462).

A number of phenomena, such as the distribution of mass and of nutrients which would result from currents running parallel to the continental slope

\section{Legend to Fig. 1 .}

Fig. I. A, a frequent pattern of isosteres south of the Celtic Sea in winter when the uppermost $75-100 \mathrm{~m}$. of water in the ocean is homogeneous and is overlying water with density and content of nutrient salts increasing downwards. B, a pattern of isosteres in winter over the continental slope, drawn to a scale of $\mathrm{I}: 4$, with no forces operative. The amount of light water which will later lie to windward is considered unlimited. C and D, cushioning of light oceanic surface water against the continental slope brought about by on-slope gales. The resistance of the solid slope to further progress of the foot of the light water is, however, absolute causing the isosteres to curl and ultimately to become vertical. Restoring Archimedean forces in D have then become zero. E, the drag of the surface wind current will draw the upper strata of stratified water with it leading to an unstable density inversion as illustrated. F, the unstable tongue of heavier water will capsize violently, leading to a homogeneous mass of mixed water extending from the surface to the depth of the bottom of the capsizing water mass. New isosteres, bracketing the capsized water mass, are so created. G, the newly formed surface water will be heavier than the surface water inshore and to seaward and will subside to form a lens, of homogeneous water at its appropriate density level and will be replaced by fresh oceanic surface water blown in from seaward. Processes D-G must be considered as simultaneous parts of a continuous process, with the line of capsizing receding from the continental slope and the maximum depth of the phenomenon increasing as the gale proceeds. Consequently the water blown on to the continental shelf of the Celtic Sea by a strong southerly gale should be entirely capsized water and richer in nutrients than it would be if it were solely oceanic surface water. Moreover, the nutrient content of the water passing on to the shelf should increase as the gale proceeds, and the depth of capsizing becomes greater. 
have been considered as means of enrichment of surface water with nutrients from deeper layers. None, considered singly, seems able to account for the observed occurrence of nutrients. The concept of capsizing of a water mass over the southern continental slope of the Celtic Sea during strong southerly gales is the first to promise a mechanism on a scale great enough to explain the observed results.

No research ship is ever likely to make direct observations of capsizing water masses during strong on-slope gales. Indeed a shipmaster is likely to take steps to get away from an area of capsizing as quickly as possible. By the time the wind had dropped sufficiently to allow of observations, much of the direct evidence would have vanished. Confirmation will need to be sought by indirect means.

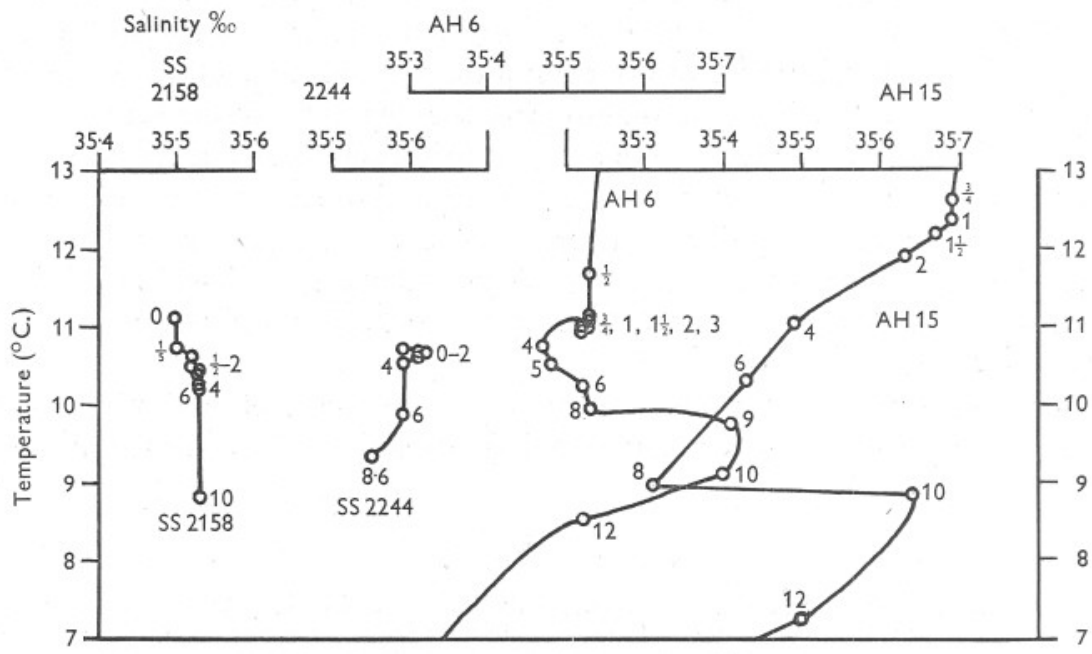

Fig. 2. Temperature-salinity relationships: on two occasions at station SS, $50^{\circ} 34^{\prime} \mathrm{N}$., $\mathrm{II}^{\circ} \mathrm{I}^{\prime}$ ' W., on the edge of the 'South Porcupine' submarine bight, south-west of Ireland (SS 2 158, I4. v. 25, and SS 2244, I9. ii. 27); at Armauer Hansen station I9I4/6 (5. vi. I4) on the southern edge of the Celtic Sea (cf. Cooper, I952, figs. 8 and 9); and at Armauer Hansen station I5 (9. vi. I4) in the North Atlantic 400 miles from the continental slope. The small figures represent depths in hundreds of metres. The diagram illustrates the vertical compression of properties which may occur in the submarine bight and to a lesser extent anywhere on the continental slope.

A greater understanding of the process of capsizing may contribute to the safety of vessels passing over the continental slope, in particular those engaged in the hake fishery.

Capsizing has to be considered as one only of a number of mechanisms peculiar to the region of the continental slope which contribute in different degrees to the enrichment of the English Channel with nutrients. Atkins's (I923) first measurements on 7 March I923 showed that the phosphate content of the English Channel at EI ( $50^{\circ} 04^{\prime}$ N., $4^{\circ} 22^{\prime}$. W.) was then very high 
(0.7I $\mu \mathrm{g}$.-atom/1.). It is of interest that the table of mean wind conditions over the western English Channel (Dietrich \& Wyrtki, I95I, used by permission of the Hydrographer of the Navy) shows that in February I 923 the monthly mean wind blew at $8 . \mathrm{I} \mathrm{m}$./ $/ \mathrm{sec}$. from direction true $214^{\circ}$, a monthly mean velocity which has never been exceeded since from any direction. None the less, detailed examination of records shows that it would be too facile to attribute the observed distribution of nutrients in March 1923 solely to capsizing water masses over the continental slope during the preceding southwesterly gales. The event needs to be remembered as one only in the complex of events we are seeking to understand.

Temperature-salinity diagrams for stations 49, 5I and 68 (Cooper, I952, fig. 4) worked by the Thor in I906 (Schmidt, I9I2) are shown in Fig. 3. The middle station $5 \mathrm{I}$ is strikingly different from stations 49 and 68 , from all others worked by the Thor and from International Station E4 $4\left(48^{\circ} 27^{\prime}\right.$ N., $6^{\circ} 35^{\prime}$ W. $)$ worked 6 days earlier. The isohaline water extended from 50 to $800 \mathrm{~m}$., suggesting that the waters at station $5 \mathrm{I}$ had been subjected to more intense vertical mixing. At all the nine deep-water stations worked, except one, marked thermal stratification of the uppermost water layers had become established. The exception was again station 5I, where the surface water was only $0.15^{\circ} \mathrm{C}$. warmer than at $100 \mathrm{~m}$., the uppermost $50 \mathrm{~m}$. being completely isothermal. The maintenance of such homogeneity in late spring must have demanded powerful forces bringing about vertical mixing.

The position of station no. $5 \mathrm{I}, 4^{\circ} 07^{\prime} \mathrm{N} ., 9^{\circ} 03^{\prime} \mathrm{W}$. shown by Cooper (I952, fig. I0), was near a dissected section of the continental slope. Any water movements in such an area should facilitate vertical mixing and capsizing there is likely to be especially strongly developed.

The Daily Weather Reports of the Meteorological Office for November I905-May I906 have been examined. The winter was not notably stormy. There were south-westerly gales (Beaufort force 7 or 8) in the area on 22 and 26 November, and a south-south-easterly gale on I8 December. The stormiest period was the first fortnight of January. These were the only gales which could have caused severe capsizing, but they were at the season suspected of being most favourable for nutrient enrichment. The north-westerly gales of 8, II and I2 February and I2 March could not have caused capsizing in the southern area. There have been many winters more favourable for capsizing than that of $1905^{-6}$.

It has been earlier suggested (Cooper, I947) that internal waves may play a part in raising nutrient-rich deep water on to the continental shelf. So they may, but now it seems that in this area their influence will be very small compared with that of capsizing. It seems more likely that some internal waves in the ocean may arise from intermittent capsizing over distant continental slopes. This is a process which could be readily established by repeated observations of temperature and salinity at standard depths at a position some 
hundreds of miles off a continental slope against which a heavy gale was known to be blowing.

The exceptionally powerful vertical thrusts visualized as occurring beneath a capsizing water mass, followed by subsiding of the relatively heavy new

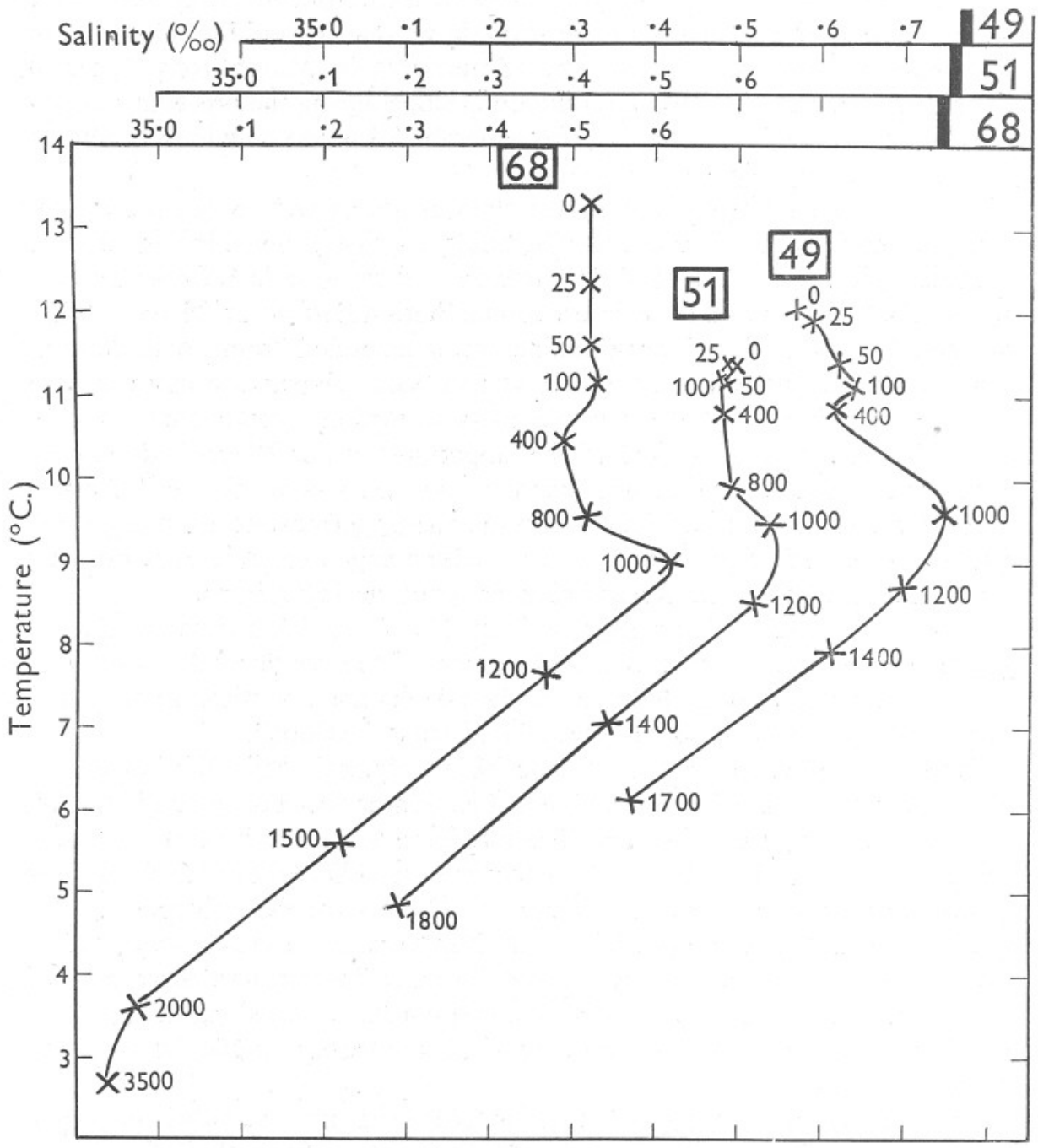

Fig. 3. Temperature-salinity diagrams for three stations (49, $5 \mathrm{I}, 68)$ worked by Thor in May 1906 (see Cooper, I952, fig. 4). The numbers refer to depths in metres.

surface water and recovery of the deeper water of the same density into a thinner but more extensive lenticular water mass at mid-depths, is a process which must necessarily initiate wave motion in the lower boundary of the 
homogeneous water. Internal waves may be a result, not a cause, of a process that leads to enrichment with nutrients of surface waters.

A stratified or laminated water mass underlying a quiescent one, already homogenized by capsizing, may be compared with the leaf-spring of a railway wagon or motor car at rest. In the open ocean, the vertical thrust due to subsequent capsizing of a water mass-if indeed such ever occurs therewould be taken up by the laminated water mass as by a leaf-spring and the energy smoothly dissipated as internal waves. There is no reason to suspect that much dissipation of energy would occur due to friction or turbulence. But against a continental slope, and especially against a strongly dissected one, this 'leaf-spring' of laminated water masses would grind forcibly, so that much of the energy of the vertical thrust due to overhead capsizing would be dissipated by turbulent mixing.

The detailed examination of the Irish records at station SS (Cooper, I952) has shown that much vertical mixing occurs between 600 and $1000 \mathrm{~m}$. Two of the most extreme occurrences are presented in Fig. 2. On occasion cascading from the north would provide a partial explanation of the observed distribution of properties, but it is clear that it cannot always do so. On some occasions the distribution of temperature has been such as to make it highly improbable that any considerable proportion of the surface water immediately overhead had been carried down. The phenomenon is one of mixing, confined to the deeper strata, without complete homogenization.

It is inconceivable that this phenomenon arises from the mixing action of surface waves. Much thought has been given to internal waves as a cause of such deep turbulence, but no records exist of internal waves in the ocean of sufficient magnitude to produce the observed distribution of properties against the slope.

'Leaf-spring' dissipation of energy beneath a capsizing water mass against a dissected continental slope promises a mechanism able to transmit to very considerable depths energy imparted to the sea surface, and of sufficient magnitude to produce the observed distribution of properties between 600 and $1000 \mathrm{~m}$.

This process of capsizing, if it can be firmly established, would influence the biological cycle in the sea in many very varied ways. The hypothesis fits qualitatively with such local observations as have been examined. It is not proven, and is presented solely as a basis for further quantitative work.

\section{SUMMARY}

Some physical processes are examined which may cause enrichment of the surface layers of the sea from deep reserves of nutrients.

Winds blowing intermittently towards a continental slope may produce vertical oscillations which bring about spillage of deeper nutrient-richer water 
from the ocean on to the continental shelf. Submarine valleys cut in the continental slope should canalize such spillage water into narrow streams.

Sandström's concept of capsizing of water masses in a high wind has been further developed for the conditions existing over a continental slope. Capsizing of water masses is more likely to enrich the surface layers over the southern rather than over the western continental slope of the Celtic Sea. Capsizing is likely to be especially intense over submarine spurs projecting from dissected regions of the continental slope.

Data collected by the Danish research ship Thor in 1906 is adduced as evidence for capsizing over a dissected slope.

Internal waves in the open ocean may possibly be created by the vertical thrusting of capsizing water masses over a continental slope.

The deeper stratified water underlying a region of capsizing has been compared with a leaf-spring of a vehicle. Dissipation of the energy of capsizing in such a leaf-spring of stratified water would produce a distribution of properties such as that often reported from the Irish investigations.

\section{ADDENDUM (AdDED IN PRoOF)}

Photographs to illustrate the process of capsizing have been obtained at the Windermere Laboratory of the Freshwater Biological Association in Dr C. H. Mortimer's (I95I) experimental tank. In this the surface layer of water may be warmed and made lighter by two hot wires stretched the length of the tank, and then labelled by means of a dye. Electric blowers simulate wind blowing over a stratified lake or sea.

In the ocean the theory of capsizing of water masses over a continental slope requires a very large reservoir of light surface water lying in the ocean to windward and opportunity for some surface water to be driven on to the continental shelf to leeward. In our area the Celtic Sea and its neighbouring channels provide such opportunity. These conditions the tank cannot provide. Although capsizing has been observed on the 'lee slope' of the tank, it has not been possible to photograph it.

When the blowers are stopped the light surface water in the tank swings from the leeward to the windward end of the tank where a process closely akin to but not identical with capsizing occurs. This is illustrated in Fig. 4. The uncoloured water is heavier than the coloured water and, in the ocean, the condition illustrated should be quickly followed by cataclysmic mixing. Though there is an element of fake in these pictures, none the less they should assist the reader to visualize the process of capsizing which has been described.

The writer is indebted to $\mathrm{Mr} \mathrm{H}$. C. Gilson, Director, for placing the facilities of the Windermere Laboratory at his disposal, to Dr Mortimer for the use of the tank and to him and Mr E. Ramsbottom for experimental and photographic assistance. 
The term 'capsizing' (see p. 455, footnote) has been discussed with hydrographers during the meeting of the International Council for the Exploration of the Sea at Amsterdam in October I95I. It was clear that to some people the word conjured up a picture of a complete turning-turtle without very much mixing. The most essential part of the process is cataclysmic mixing; overturning is also essential, but in any one incident it need not be complete.

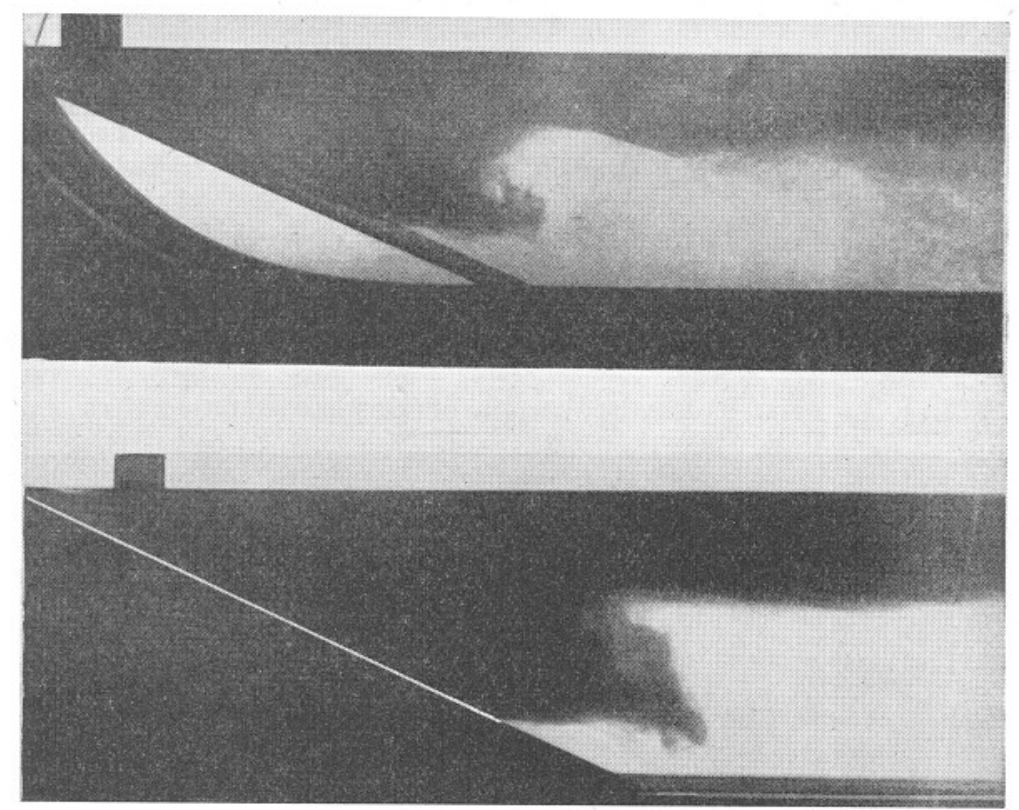

Fig. 4. Two photographs in a model tank to illustrate the process of capsizing of water masses over a continental slope. In both pictures the continental slope is represented by a sheet of metal; in the lower one the dead water beneath the plate has been masked and the boundary between the capsized water and the 'continental slope' has been lightly touched up.

The French word culbuter, meaning 'to upset violently resulting in a confused heap or jumble', expresses much better than any English word what is in mind. Mr G. A. Steven, who suggested the apt word 'cascade' for another kind of event over the continental slope, feels strongly that 'culbute' is much the more descriptive word and that its introduction into oceanography is justified. Oceanographers, if they find the need to use the hypothesis, are left to choose the term they think most fitting. If accepted for use in English speech the pronunciation of 'culbute' would be better anglicized. 


\section{REFERENCES}

Atkins, W. R. G., 1923. The phosphate content of fresh and salt waters in its relationship to the growth of the algal plankton. Fourn. Mar. Biol. Assoc., Vol. I3, pp. II9-50.

Cooper, L. H. N., I947. Internal waves and upwelling of oceanic water from middepths on to a continental shelf. Nature, Lond., Vol. 159, p. 579.

- I952. The physical and chemical oceanography of the waters bathing the continental slope of the Celtic Sea. Fourn. Mar. Biol. Assoc., Vol. 30, pp. 465-5ro.

Cooper, L. H. N. \& VAUX, D., I949. Cascading over the continental slope of water from the Celtic Sea. Fourn. Mar. Biol. Assoc., Vol. 28, pp. 719-50.

DIETRICH, D. \& WYRTKI, K., I95I. Tables of monthly mean wind vectors and components for the English Channel as deduced from barometric gradients over the years I88I to I949 (less 1943). Admiralty: Hydrographic Department (Oceanographic Branch).

Harvey, H. W., 1928. Biological Chemistry and Physics of Sea Water, I89 pp. Cambridge.

Mortimer, C. H., I95I. The use of models in the study of water movements in stratified lakes. Proc. Int. Assoc. Theoretical and Applied Limnology, Vol. II, pp. $254-60$.

SANDSTRÖM, J. W., I9I8. The hydrodynamics of Canadian Atlantic waters. Canadian Fisheries Expedition, 1914-15, pp. 221-343. Ottawa.

Schmidt, J., I912. Hydrographical observations. Rep. Danish Ocean. Exp. 1908-1910, Vol. I, pp. 53-75. Copenhagen. 